\title{
REESTRUTURAÇÃO E CENTRALIDADE: BREVES NOTAS SOBRE A CIDADE DE JOÃO PESSOA
}

\author{
Josineide da Silva Bezerra \\ Historiadora, Mestre em Geografia pela UFPB e Professora Substituta da Universidade \\ Estadual da Paraíba ${ }^{1}$
}

\section{Luciana Medeiros de Araújo}

Geógrafa, Mestre em Geografia pela UFPB e Professora Substituta da Universidade Estadual da Paraíba

\section{Introdução}

Neste texto, desenvolvemos uma reflexão acerca da cidade de João Pessoa, voltando-nos aos novos padrões de centralidade que nela se realizam, os quais exercem influências na sua reestruturação urbana, a partir de mudanças verificáveis no papel ou nas funções do seu centro tradicional. A escala intra-urbana compõe o nosso referencial, por meio da qual enfatizamos estratégias de consumo traçadas por agentes produtores do espaço urbano aqui recortado, sejam esses agentes públicos ou privados.

A nossa leitura esteve ancorada em um olhar que buscou reconhecer e registrar a paisagem urbana, estando atento à disposição e às redefinições dos fixos e fluxos que essa paisagem comporta. Portanto, buscamos os seus resíduos históricos: as rugosidades ${ }^{3}$ de uma cidade quatrocentenária, com suas ruas, equipamentos e monumentos, com a distribuição espacial de suas moradias. Rugosidades que possibilitam uma leitura das diferentes temporalidades e especificidades da produção/reprodução do seu espaço intra-urbano.

\footnotetext{
${ }^{1}$ Contato: prof.neide@uol.com.br.

2 Contato: araujolm@uol.com.br.

3 Para Milton Santos (2002: 40) as rugosidades dizem respeito àquilo que "fica do passado como forma, espaço construído, paisagem", estando inscritas na materialidade da cidade.
} 
Um espaço que comporta novas configurações, as quais, sobrepostas aos seus resíduos históricos, nos convidam a pensar os vários caminhos trilhados pela cidade no decurso da sua expansão e aguçam o nosso olhar quanto à sua história, na qual estão inscritas a evolução e a composição das suas formas-conteúdos. Daí, então, um olhar que se emociona, a partir do qual poderíamos concluir: "a cidade deu às costas ao o rio que the serviu de nascedouro - encantou-se com o canto das ondas" (Vídeos Para'iwa, 1995).

A importância do debate quanto às novas centralidades está relacionada aos impactos que as mesmas impõem ao cotidiano das pessoas e à estrutura interna das cidades, a exemplo da necessidade de abertura e ampliação de novas vias de circulação. Por isso, consideramos a pertinência de estudos que busquem semelhanças e diferenças na dinâmica intra-urbana verificável nas mais diferentes cidades brasileiras (SPOSITO, 2001).

Ao fitarmos as tramas citadinas de João Pessoa, orientamo-nos a partir de abordagens sistematizadas por Villaça (2001), muito embora esse autor aprecie as principais metrópoles do país, por intermédio das quais analisa a dinâmica que norteia os seus padrões de centralidade. A rigor, portanto, esses estudos não deveriam ser tomados como referenciais. Entretanto, à luz desse estudioso, voltando-nos às categorias que ele evidencia, como centralidade, centros urbanos ou segregação, admitimos que seja possível contribuirmos com o debate acerca de novas centralidades quanto a pequenas ou médias cidades entre as quais incluímos João Pessoa ${ }^{4}$.

Motivadas por esse intuito, construímos o nosso texto sob o entendimento de que a cidade é uma espacialidade cartografável, a qual pode ser apreendida como uma paisagem que "se caracteriza por uma dada distribuição de formas-objetos, providos de um conteúdo técnico específico" (SANTOS, 2002: 103). Em um dado espaço urbano, marcado por ritmos e ambiências peculiares, a sociedade interfere nessas formas-objetos, atribuindo-Ihes novas funções e novas formas.

Portanto, compreendemos a cidade como um produto social, revestido de historicidade. Igualmente, a reconhecemos como condição para a realização de diferentes ações socioeconômicas, as quais delineiam os padrões de produção,

\footnotetext{
${ }^{4}$ As cidades médias podem ser pensadas, por exemplo, a partir da disponibilidade de seus serviços e equipamentos urbanos, desempenhando papéis intermediários na rede urbana regional (SPOSITO, 2004).
} 
circulação e consumo nela vivenciados, relacionados à lógica de um dado sistema produtivo, no caso, o capitalismo. Não obstante, para além dessa lógica, tais ações revelam, também, as "singularidades da vida humana", como assinala Trindade Júnior (2001: 152).

Quanto a João Pessoa, a (re)produção do seu espaço intra-urbano será pensada por meio de dois tempos. O primeiro voltar-se-á à sua gênese, em meio ao processo de colonização do país, a partir do século XVI. O segundo estará voltado à fase de aceleração da industrialização brasileira, notadamente a partir da segunda metade do século $X X$, quando novas práticas socioespaciais passaram a contornar a sua dinâmica urbana.

\section{João Pessoa: entre centro tradicional e novas centralidades}

O núcleo inicial da cidade de João Pessoa remonta à fundação da Capitania Real da Paraíba, efetivada no final do século XVI, como mecanismo para garantir a conquista do litoral setentrional das terras coloniais, indo-se além das fronteiras da Capitania de Pernambuco. Inscrita no processo de expansão mercantil européia, quando da colonização do Brasil, apresenta uma singularidade em relação às demais capitais litorâneas: foi edificada distante do mar, a partir da margem direita do rio Sanhauá, no estuário do rio Paraíba caminho tomado pelos portugueses no processo de conquista do território.

Esse núcleo distribuía-se em meio a uma topografia irregular, formada por dois compartimentos: a Cidade Baixa, que ocupava um pequeno trecho da várzea direita do Rio Sanhauá, e a Cidade Alta, estendida por sobre o Baixo Planalto Costeiro. Na então batizada Filipéia de Nossa Senhora da $\mathrm{Neves}^{5}$, os primeiros equipamentos comerciais, religiosos, residenciais e administrativos foram instalados, modelando o seu tecido urbano e as suas estruturas socioespaciais, marcadas pela precariedade dos equipamentos, pela modéstia das construções e pelo traçado tortuoso de suas ruas (MAIA, 2000).

\footnotetext{
5 No decorrer de sua história, João Pessoa já apresentou outras diferentes designações: Nossa Senhora das Neves, Filipéia de Nossa Senhora da Neves, Frederica e Parahyba. O nome atual Ihe foi atribuído em 1930.
} 
Com um crescimento urbano lento, durante mais de três séculos, a cidade de João Pessoa manteve seu pequeno tecido urbano circunscrito ao sítio original, sendo assim descrita por Aires de Casal, no início do século XIX:

\begin{abstract}
Cidade medíocre, aprazível, populosa (...), sobre a margem direita, e três léguas acima da embocadura do rio (...), ornada com casa de misericórdia e seu hospital, um convento dos Franciscanos, outro de Carmelitas, terceiro de Beneditinos (...), cinco ermidas (...), dois elegantes chafarizes de boas águas. (CASAL, 1976: 275).
\end{abstract}

Até o final do século XIX os seus limites urbanos praticamente se restringiam à Cidade Baixa e à Cidade Alta, as quais compunham uma cidade que se desenvolveu sob um padrão comum a diferentes cidades coloniais. À chamada Cidade Baixa foram reservadas as atividades comerciais, a partir das quais foi sendo contornado o que veio a ser o centro tradicional de João Pessoa. Já a Cidade Alta foi configurada como espaço de instalação das instituições religiosas e de moradia, ocupada por um segmento mais seletivo da população. Juntas, essas duas áreas nos remetem à chamada Cidade Tradicional (MAIA, 2000).

Destaquemos que é a partir dos padrões de produção, circulação e consumo no/do espaço que uma área da cidade torna-se central. Logo, a dinâmica que delineia esses padrões tem repercussão direta na realização do caráter de centralidade dessa área. Portanto, o centro de uma cidade é moldado na medida em que é ocupado como local de vivência cotidiana por uma comunidade/sociedade: "será um conjunto vivo de instituições sociais e de cruzamento de fluxos de uma cidade real" (VILLAÇA, 2001: 238).

Daí o Varadouro, na Cidade Baixa, a partir do seu porto, da alfândega e da estação de trem, ter abrigado o centro comercial tradicional ou principal de João Pessoa. Nele, merece destaque a Rua das Convertidas - atual Maciel Pinheiro, onde encontramos, inclusive, o imponente prédio da Associação Comercial do Estado. Consumindo-se esse espaço, foi configurada a expansão da cidade.

Essa lógica, como um vetor, ao longo do século $X X$, foi imprimindo novos movimentos, novos ritmos, ampliando-se o centro comercial, chegando à Cidade Alta. Uma ampliação que esteve relacionada a intervenções públicas, como a urbanização do Parque Sólon de Lucena (Lagoa) e a abertura de novas vias de circulação, as quais impulsionaram a ocupação de áreas vizinhas ao núcleo 
inicial. Nessas duas porções, reconfigurou-se o centro tradicional da cidade, quanto ao qual, trazemos a imagem a seguir.

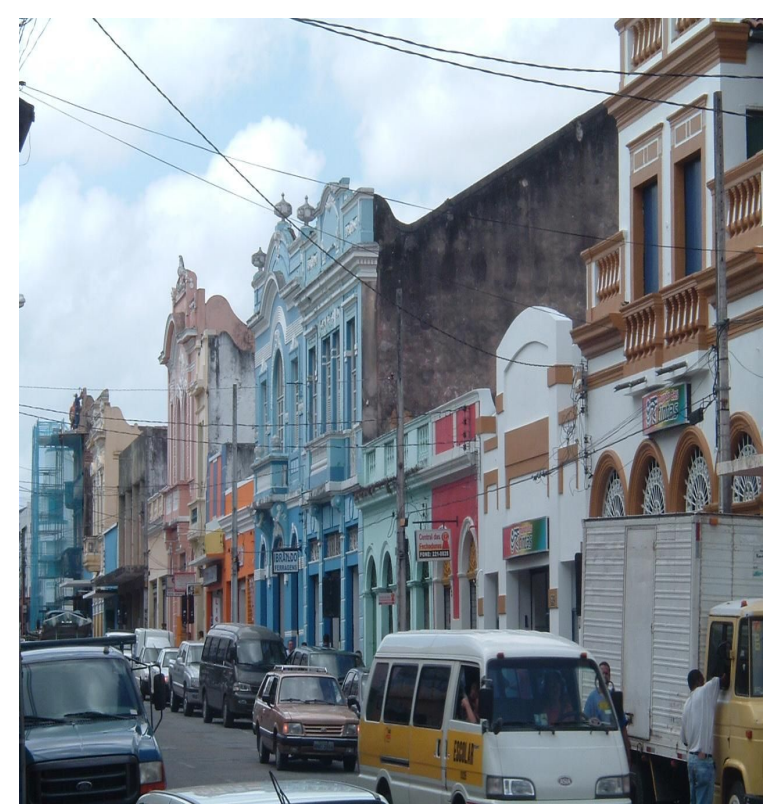

Foto 01. Padrão construtivo e serviços oferecidos Centro Tradicional. Foto: Josineide Bezerra, set 2007.

Nos últimos trinta anos, contudo, observamos uma intensificação do deslocamento da população de maior renda para áreas mais "distantes", as quais passaram a abrigar bairros residenciais, especialmente localizadas na orla ou em suas proximidades. Esse deslocamento imprimiu novas dinâmicas na ocupação do centro tradicional, tendo rebatimentos na sua gradativa transformação.

Até então, este centro apresentava uma maior dinâmica urbana, sob a convergência de um grande fluxo de pessoas, em busca dos mais diversificados e sofisticados serviços. Nele, encontrávamos os principais cinemas, restaurantes, hotéis, magazines, estabelecimentos de ensino, escritórios e consultórios de profissionais liberais. Era, também, um lugar de moradia, sobretudo da classe média, a qual se servia de tais serviços, ou seja, se servia do centro da cidade.

Segundo Villaça (2001), a tendência ao "abandono" do centro, verificável nas diferentes metrópoles brasileiras, ganha forma quando os segmentos mais abastados entre os citadinos já não Ihe têm como itinerário, seja para o trabalho, 
para o consumo de serviços ou para o lazer. Com efeito, identificamos esse abandono do centro tradicional de João Pessoa, apesar dessa área ainda ser um espaço de moradia - mesmo que limitadamente e sob um perfil mais popular - e manter um perfil comercial.

Centro que é, também, via de acesso à rodoviária e via de circulação para a maioria das linhas de ônibus que trafegam na cidade. Isso é mais expressivo no Varadouro, onde encontramos várias edificações fechadas, mal conservadas ou abandonadas, revelando uma imagem de desgaste efetivo daquele espaço. Em tempo, lembramos que a Prefeitura Municipal, recentemente, mudou de endereço e não mais está ali instalada.

Inscrito na dinâmica que reorienta a ocupação do espaço intra-urbano, esse movimento de abandono do centro tradicional pode ser analisado a partir das práticas espaciais que reestruturam a cidade, como a fragmentação e a segregação. Esta última pode ser definida como "um processo segundo o qual diferentes classes ou camadas sociais tendem a se concentrar cada vez mais em diferentes regiões gerais ou conjuntos de bairros na metrópole", afirma Villaça (2001: 142, grifos do autor), ressaltando, ainda, que é possível tipificar a segregação a partir do par dialético centro-periferia.

Ainda segundo o referido autor, a diferenciação deste par, especialmente quando a metrópole é o espaço de análise, evidencia-se pela melhor qualidade e maior disponibilidade dos serviços urbanos públicos e privados existentes no centro. A periferia, por seu turno, é marcada pela precariedade de seus equipamentos e serviços, bem como pela maior distância em relação às áreas mais centrais.

Apesar de ser entendida como uma cidade média, é possível pensarmos essa prática espacial em relação a João Pessoa. Para tanto, é necessário que cheguemos a um segundo tempo, quando a cidade passou e ainda passa por um processo de adensamento populacional, com repercussão direita, mas não apenas por isso, sobre a extensão do seu tecido urbano. O seu crescimento é vivenciado na esteira do processo de industrialização e modernização produtiva que marcou todo o país, a partir da segunda metade do século $\mathrm{XX}$, especialmente as suas capitais.

Nesse contexto, de acordo com Maia (2000: 36), a população da cidade cresceu a uma média de $50 \%$ a cada década - um crescimento que repercutiu 
junto às relações cidade-campo, com evidentes implicações quanto ao lugar de moradia das pessoas. Éramos 95.953 habitantes em 1950 e passamos a 497.599, em 1991 - os dados desse ano indicam que mais de $43 \%$ desses habitantes não são naturais do município. O Censo 2000 indica uma população de quase 600 mil habitantes (IBGE, 2000).

Portanto, entre migrantes, bondes, pontes e avenidas, a cidade vai se espraiando, sob novos padrões produtivos, acostados a políticas públicas urbanas que privilegiam a lógica do capital. Uma urbanização relacionada a interesses de grupos econômicos que se apropriam seletivamente do espaço da cidade, segregando-o. Assim, João Pessoa se expande, de forma contínua ou descontínua, para áreas periféricas ao seu centro tradicional.

De modo mais expressivo, essa expansão é impulsionada por ações combinadas entre o Estado e as grandes corporações privadas, como as incorporadoras, as construtoras e os agentes imobiliários. Assegura-se, pois, a implantação de equipamentos de infra-estrutura e de atributos seletivos que definem os valores de uso e de troca de novas áreas - a exemplo das avenidas Epitácio Pessoa e Beira Rio, que cortam a cidade de oeste a leste; e do Anel Rodoviário, que facilita a circulação para as cidades e estados circunvizinhos.

Reconhecemos que a estruturação das vias de circulação exerce um poderoso papel na produção do espaço intra-urbano, porque elas são imprescindíveis aos deslocamentos e à acessibilidade dos indivíduos aos mais diferentes locais de moradia, de trabalho e de consumo. Por isso, resgatamos Villaça (2001: 21): "a estruturação do espaço intra-urbano é dominada pelo deslocamento do ser humano, enquanto portador da mercadoria força de trabalho ou enquanto consumidor". O autor chama atenção, igualmente, para o fato de que é o transporte de pessoas e não o de mercadoria, que torna o espaço intra-urbano mais heterogêneo.

Assinalemos, ainda, que os anos sessenta e seguintes vão ser marcados pela construção dos conjuntos habitacionais, os quais tomaram diferentes direções, principalmente para o sudeste - efetivados por intervenções públicas, financiados por meio de recursos governamentais. Essas intervenções contribuíram para estender o tecido urbano, descentralizando a sua ocupação, promovendo-se a realização do que Maia (2000) chamou de Cidade Modernizada 
- uma cidade marcada pelo estigma da complexidade, cujas diferenças socioespaciais se tornaram cada vez mais evidentes.

A Cidade Modernizada - imagem contemporânea - é permeada por essa dinâmica, sendo por ela modelada. Nesta cidade, o que se convencionou chamar de periferia ganha novos contornos, sob a marca da heterogeneidade e da descentralização, o que nos leva a uma periferia que compõe novas estruturas de concentração, num processo que envolve, ao mesmo tempo, complexidade e contrastes, contradições. Com efeito, afirma Sposito:

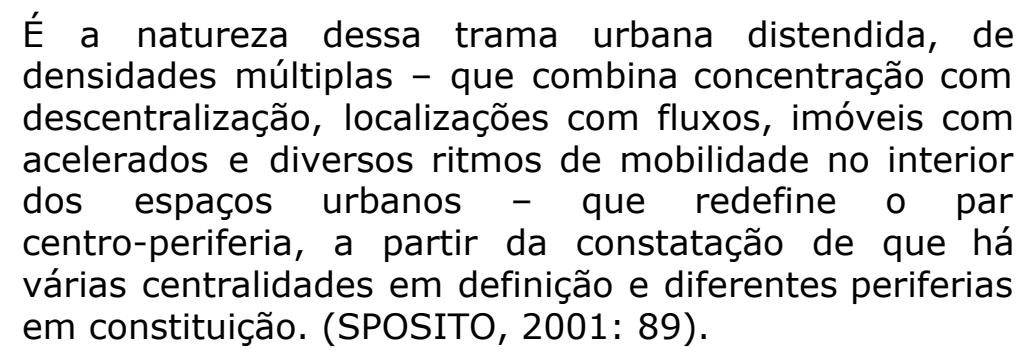

Nesse curso, novas centralidades são constituídas, impulsionadas pela expansão urbana, bem como por diversos atributos seletivos, definidores das formas de consumo e de apropriação dos diferentes espaços intra-urbanos. A partir destas formas, é possível assinalarmos duas dinâmicas paralelas e articuladas entre si, que conferem às cidades uma feição multicêntrica e/ou policêntrica (SPOSITO, 2004).

Voltando-se a cidades médias, essa estudiosa considera que a feição multicêntrica está associada ao

\begin{abstract}
aumento do número de áreas centrais, em função do aparecimento e multiplicação de subcentros (já que as cidades estão mais extensas e descontínuas territorialmente), de eixos comerciais e de serviços especializados ou não e de shopping centers (SPOSITO, 2004: 375).
\end{abstract}

De outro modo, nesse mesmo texto, a referida autora associa a feição policêntrica à estratificação social e ao perfil do consumidor, considerando não somente o seu poder de compra, mas também o meio de transporte, particular ou coletivo, por ele utilizado em seu deslocamento.

Pensemos essas duas feições em relação a João Pessoa. 
A multicentralidade poderia ser associada à periferia sul, modelada por meio dos grandes conjuntos residenciais, entre os quais chamaríamos atenção para Mangabeira. Com uma população aproximada de 70 mil habitantes (IBGE, 2000), esse conjunto apresenta-se como área de expansão, com uma grande diversificação da atividade comercial e de serviços no contexto da cidade.

Essa diversificação está relacionada aos bancos, mercados, escolas, supermercados, cartórios, fóruns, clínicas e hospitais existentes em Mangabeira. Tais equipamentos atendem as demandas mais cotidianas não só dos seus moradores, mas também dos bairros circunvizinhos. Por isso mesmo, é possível destacarmos essa área como um subcentro - categoria que, segundo Villaça, corresponde a uma

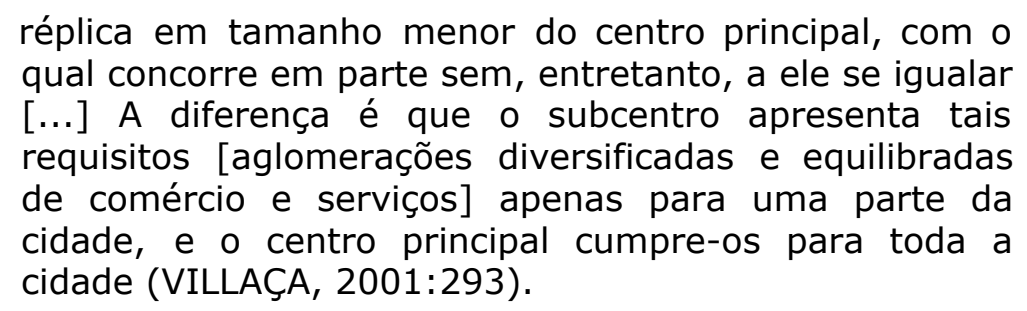

Desse modo, Mangabeira desempenha um papel complementar de centro de atividades socioeconômicas em relação ao centro principal da cidade. Algumas das empresas nele instaladas são filiais de grandes lojas comerciais e de serviços, cujas matrizes estão localizadas nas áreas centrais e valorizadas de João Pessoa, tais como: Unimed, Lojas Maia, Thiago Calçados, Armazém Paraíba, laboratórios de análises clínicas, como o Maurílio de Almeida, ou cursos de inglês, como o CCAA.

Por outro lado, quanto à policentralidade, realizada sob uma forma mais segmentada, ordenada por e para determinadas parcelas da população, atendendo um padrão de consumo mais seletivo, destacaríamos o litoral norte de João Pessoa, a partir dos bairros de Tambaú e Manaíra - os quais estão intensamente interligados, sendo tomados como exemplares neste texto.

A seguir, apresentamos a figura 01, na qual, por meio da divisão de bairros da cidade, recortamos a área que identificamos como centro tradicional e as áreas representativas de novas centralidades em João Pessoa. 


\section{Novas centralidades em João Pessoa}

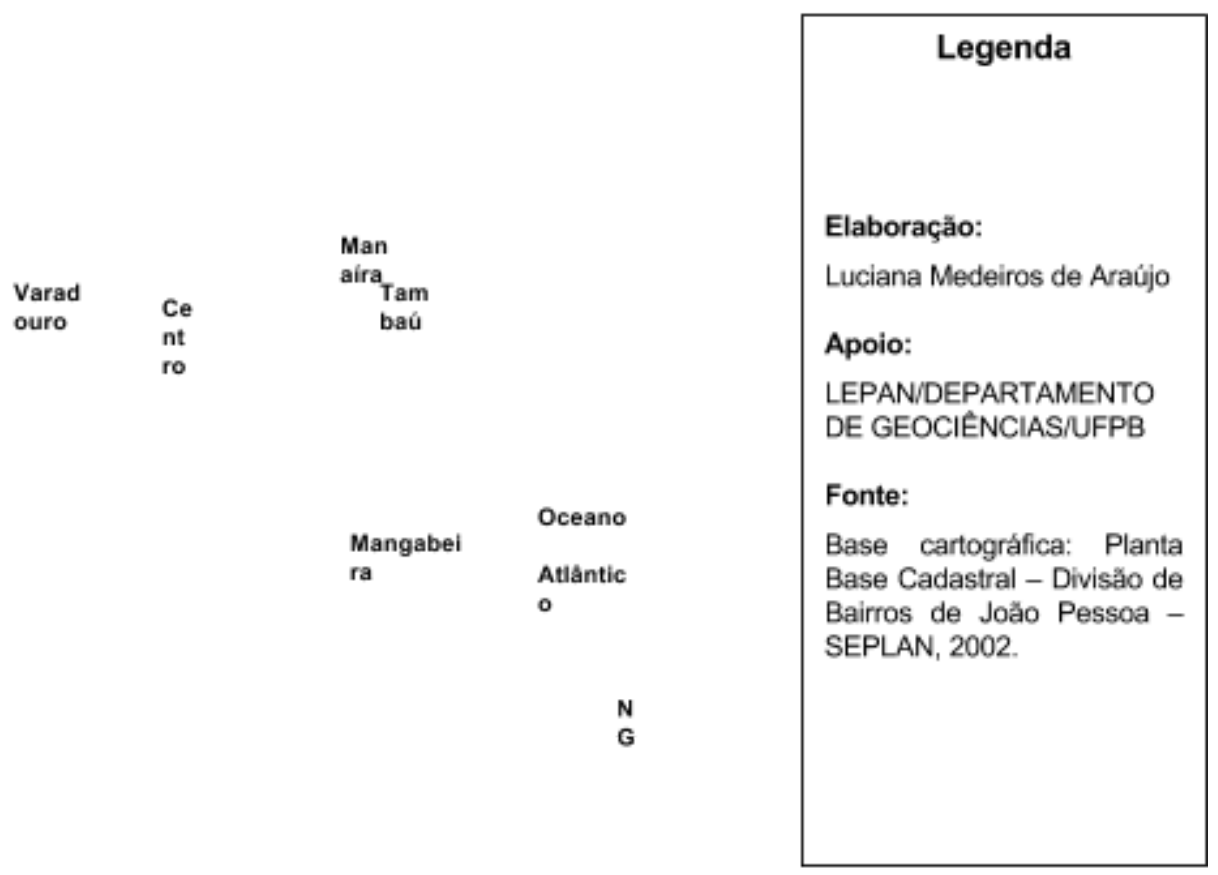

Figura 02. Recorte do centro tradicional e de novas centralidades na cidade de João Pessoa (PB).

Apresentamos, em seguida, uma seqüência de fotografias dos bairros de Manaíra e Mangabeira, as quais compõem uma representação do padrão construtivo e dos serviços oferecidos nessas áreas da cidade. 
it

|

I

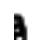

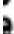

1

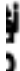

1

|

I

1

j)

1

I

a

i

i

it

ts

e

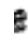

1

ij

t.

I. 
Sedimentando essa discussão, ainda buscamos as reflexões de Sposito (2001), ao assinalar dois vetores que norteiam a relação centro-periferia, mesmo que não os reconheça como únicos. A estudiosa menciona os novos padrões de moradia associados às classes média e alta - relacionados a um tipo de segregação. Ressalta, igualmente, os novos mecanismos/estratégias de realização do consumo de mercadorias e serviços, revelando a fragmentação como uma categoria fundamental quanto ao debate relativo à cidade pós-industrial - aquela cidade que, também produto do capitalismo, se realiza sob a industrialização, como espaço de consumo.

Na compreensão de Villaça (2001), os novos padrões de moradia ganham um destaque especial na análise dos espaços intra-urbanos, em meio a diferentes demandas. Ora como uma disputa social por localização, a qual é contornada pela apropriação dos lugares mais "nobres" da cidade, onde o habitar reveste-se de um valor de uso e de um valor de troca, como investimento. Ora como uma disputa pelo controle sobre o tempo de deslocamento das pessoas um controle que permite uma moradia de maiores dimensões ou um habitar sob apelos mais subjetivos, como modismo e prestígio.

Destaquemos, ainda, os apelos propalados pelos agentes imobiliários, relativos à garantia da conquista de uma melhor "qualidade de vida" na cidade, imprimindo-se aos condomínios e loteamentos fechados, instalados nas áreas periféricas, o signo da segurança ou da incorporação de espaços verdes, mais afastados da "desordem" cotidiana do urbano. Ou signo de uma auto-segregação, ante a convivência com os iguais. Aliás, esses locais de moradia remodelam as áreas em seu entorno, alterando-lhes o conteúdo.

Em tempo, lembramos que tanto Villaça quanto Sposito reconhecem que os contornos que sinalizam a segregação e a fragmentação como categorias de análise dos espaços intra-urbanos são bem abrangentes. Isso porque, a dinâmica urbana também comporta ações de resistência cultural e valores étnico-religiosos, entre outros, sendo estes bastante identificáveis nas diferentes estratégias de vivência nas metrópoles.

No entanto, acreditamos que os vetores destacados - os novos padrões de moradia e as novas estratégias de consumo - já em muito contribuem para pensarmos a produção dos bairros de Tambaú e Manaíra, apresentados como exemplos relativos à realização da policentralidade em João Pessoa. Dessa 
forma, entendemos a pertinência de assinalarmos alguns dados arrolados por Vasconcelos Filho (2003), em seus estudos acerca do litoral norte.

De acordo com esse autor, entre os anos de 1980 e 2000, 284 novos edifícios, 1162 casas, 105 lojas comerciais e 21 hotéis foram construídos nesses bairros. Além disso, neles encontramos serviços e equipamentos como mercados públicos, clínicas médicas, agências bancárias, colégios, supermercados, centros empresariais e os maiores shoppings da cidade. Comportam, ainda, 42 unidades industriais, 505 comerciais e 577 de serviços. As cinco imobiliárias recortadas para aplicação dos seus questionários de pesquisa apontam esses bairros com uma ocupação perfilada entre a classe média e a classe alta. Esses agentes apostam no aumento de investimentos e no crescimento dessa área, sendo a localização o seu principal atrativo.

Tais informações contribuem para conferir a essa área da cidade uma nova centralidade, a qual, sob a lógica capitalista, configura-se como a mais importante, ante o seu caráter seletivo, atendendo as demandas dos segmentos sociais de maior renda. Uma nova centralidade que, minimizando o tempo de deslocamento, se realiza por meio dos fluxos de pessoas, mercadorias, serviços e capitais; por intermédio de altos padrões de consumo ou da oferta de trabalho nela identificável.

À luz de um capitalismo globalizado, novos ritmos e padrões de produção, circulação e consumo são impressos à sociedade, sobretudo à sociedade urbana. Redesenham-se novas formas de apropriação do/no espaço, evidenciando as contradições inerentes à vida urbana: a luta de classes; os interesses públicos e privados; as diferentes concepções de valor de uso e de troca; as aspirações e necessidades coletivas e individuais.

Claro, essas novas formas não eliminam, simplesmente, as permanências inscritas sob um tempo de longa duração, aquele que, no caso de João Pessoa, remonta à história colonial. Novas e tradicionais formas estão justapostas, interrelacionadas. Entretanto, fora de seus novos fluxos e escolhas, os segmentos mais abastados da cidade não mais vivenciam o centro tradicional, esvaziando-o. Neste centro, temos uma ausência que é não de pessoas, mas de pessoas que têm um grande poder de demarcar as prioridades para toda a cidade. Nesta ausência, a violência - que vem aniquilar a "frágil simbiose centro-classe média e média alta", marginalizando-o, afirma Villaça (2001: 154). 
Isso nós reconhecemos, mas também sabemos que o centro tradicional de João Pessoa continua especialmente voltado ao setor terciário, sendo ainda um local de moradia, de trabalho e de lazer para muitos de nossos concidadãos, notadamente para os segmentos mais populares da cidade. Nesse sentido, a mudança do conteúdo econômico e social desse centro tem promovido uma "degenerescência de seus usos e de seu patrimônio imobiliário que tem, muitas vezes, um valor histórico e simbólico significativo", conforme ressalta Sposito (2004:375).

No entanto, ele está "vivo", mesmo que sejamos tentados a percebê-lo a partir da sua "morte". Não nos esqueçamos que os Três Poderes lá se encontram, bem como algumas paisagens que permanecem compondo a identidade da cidade, como a Lagoa ou o Ponto de Cem Réis - uma praça que ainda se aproxima da Ágora vivenciada pelos gregos.

Entre as tradicionais e emergentes formas, como uma recomendação que Ihes serve, lembramos Peter Burke, quando reconhece que, "segundo Braudel, a contribuição especial do historiador às ciências sociais é a consciência de que todas as 'estruturas' estão sujeitas a mudanças, mesmo que lentas" (1997: 55).

\section{Referências bibliográficas:}

BURKE, Peter. A Escola dos Annales (1929-1989): a Revolução Francesa da historiografia. São Paulo: Fundação Editora da UNESP, 1997.

CASAL, Aires. Corografia Brasílica. Belo Horizonte: Itatiaia; São Paulo: Editora da Universidade de São Paulo, 1976.

IBGE. INSTITUTO BRASILEIRO DE GEOGRAFIA E ESTATÍSTICA. Censo Demográfico 2000. Disponível em <http:// www.ibge.gov.br>. Acesso em abr de 2007.

MAIA, Doralice Sátyro. Tempos lentos na cidade: permanências e transformações dos costumes rurais em João Pessoa-PB. São Paulo: Universidade de São Paulo, 2000. (Tese de Dourado em Geografia Humana)

SANTOS, Milton. A Natureza do Espaço: Técnica e Tempo. Razão e Emoção. São Paulo: Edusp, 2002. 
SPOSITO, M. E. Beltrão. A urbanização da sociedade: reflexões para um debate sobre as novas formas espaciais. In: DAMIANI, Amélia et al. (Orgs). O espaço no fim de século: a nova raridade. São Paulo: Contexto, 2001.

- O chão em pedaços: urbanização, economia e cidades no estado de São Paulo. 2004. Tese (Livre Docência). Universidade Estadual Paulista, Presidente Prudente.

TRINDADE JÚNIOR, Saint-Clair Cordeiro da. Sujeitos políticos e territorialidades urbanas. In: DAMIANI, Amélia et al. (Orgs). O espaço no fim de século: a nova raridade. São Paulo: Contexto, 2001.

VASCONCELOS FILHO, João Manoel de. A produção e reprodução do espaço urbano no litoral norte de João Pessoa: a atuação dos agentes imobiliários. Recife: Universidade Federal de Pernambuco, 2003 (Dissertação de Mestrado em Geografia).

VÍDEOS PARAÍBA. Produção PARAÍ'WA. 1995. Videocassete (25 min) VHS/NTSC, color.

VILLAÇA, Flávio. Espaço intra-urbano no Brasil. São Paulo: Studio Nobel: FAPESP: Lincoln Institute, 2001. 